Richard Machin

Lecturer in Social Welfare Law, Policy and Advice Practice

School of Health and Social Care

Department of Social Work and Social Welfare Law

The Brindley Building, Leek Road, Stoke-on-Trent, ST4 2DF

Tel: 01782295965

Email: richard.machin@staffs.ac.uk

Made to Measure? An analysis of the transition from Disability Living Allowance to Personal Independence Payment 


\section{Made to measure? An analysis of the transition from Disability Living Allowance to Personal Independence Payment}

Richard Machin ${ }^{1}$

Social Welfare Law, Policy and Advice Practice, Staffordshire University

As part of the government's programme of welfare reform Personal Independence Payment (PIP) is replacing Disability Living Allowance (DLA) for people of working age. This will have a significant impact on a wide range of disability benefit claimants. This article examines the government's rationale for replacing DLA with PIP, the key technical differences between the two benefits and the role that disability benefits can play in reducing poverty. The introduction of PIP has led to considerable debate in the social welfare law sector about the scope, purpose and assessment of social security benefits for the disabled. These issues are explored with reference to the first Gray Review of PIP (2014) and the United Nations Committee on the Rights of Persons with Disabilities Inquiry (2016) into the impact of the UK Government's policies on disabled people.

Keywords: Personal Independence Payment; welfare reform; disability benefits

\section{Introduction}

The Welfare Reform Act (WRA) 2012 (sections 77 to 95) provides the legislative framework for Personal Independence Payment (PIP). PIP is replacing Disability Living Allowance (DLA) for claimants of working age and is intended to assist with costs associated with disability or long-term health conditions. Like DLA, PIP is a non-means tested and non-taxable benefit with two components: a mobility component based on the claimant's ability to get around, and the daily living component based on the ability to perform a range of daily living activities (sections 78 and 79 of the WRA). Entitlement is based on an individual assessment by an approved healthcare professional and all awards are subject to periodic review. PIP was introduced for new claimants from April 2013, and by 2018 it is expected that all existing DLA claimants will be reassessed for PIP (Kennedy, 2015).

Given the relatively short history of PIP there is a lack of systematic analysis on the impact of this disability benefit, although much has been written and debated in the press and amongst politicians, practitioners and claimants. The first part of this article analyses the Government's rationale for replacing DLA with PIP, examines the technical differences between the two benefits and considers the impact on a range of claimants. The second section of the article focuses on the scope of the first Gray Review of PIP (Gray, 2014). The Review was a requirement of the WRA 2012 and the terms of reference and limitations of this report will be analysed. The article analyses in detail three key areas considered by the Gray Review which are central to an analysis of the transition from DLA to PIP: the claimant experience, the collection of evidence and assuring fairness and consistency. Attention is to given to the fragile balance between the public purse and the needs of disabled claimants. In July 2016 a call for evidence for the second Gray Review of PIP was published (DWP, 2016a). This consultation is now closed with the findings of the second review expected to be published in 2017.

\footnotetext{
${ }^{1}$ Email: Richard.machin@staffs.ac.uk
} 
The final part of the article analyses the findings of the UN Committee on the Rights of Persons with Disabilities Inquiry into the impact of government policy on disabled people. The Inquiry examined the cumulative impact of legislation and policies adopted by the government on social security schemes, work and employment. This article focuses on the Committee's recommendations in relation to PIP and the Government's response to the report. In rejecting the findings of the report the UK government has restated its commitment to supporting disabled people. The article will examine the Government's defence of their record in relation to disability benefits and explore the ways in which the media has both reported and influenced public opinions on social security benefits such as PIP.

\section{The transition from Disability Living Allowance to Personal Independence Payment}

DLA was introduced in 1992 replacing Attendance Allowance and Mobility Allowance for children and adults under the age of 65 (Henry, 2014). There are striking similarities between the aims of the Conservative Government of 1992 in introducing DLA and the intentions of the coalition government and their welfare reform programme implemented twenty years later through the WRA of 2012. A key objective of the 1992 reform of disability benefits was to better target funds to disabled claimants in most need (Daly and Noble, 1996). The Department of Social Security (1990) recognised that change was needed to improve the structure of benefits for disabled people thus making it more attuned to their needs, echoing the sentiment of the equality impact assessment for PIP with a focus on supporting those with greatest need to lead full and independent lives (DWP, 2012a).

A key feature of DLA was a move to a self-assessment model (largely welcomed by both claimants and their representatives) with claimants describing the impact of their disability or health problems on a claim form running to over 40 pages. It was hoped that this would reduce the need for formal medical examinations with adjudication officers being able to determine entitlement on the basis of clear evidence from claimants, supported where necessary with evidence from a GP or consultant. The parallels between the introduction of DLA and PIP do not end with the political aims of the retrospective governments; problems with delays in decision making are a feature of both benefits. The House of Commons Social Security Committee (1993) reported a significant backlog of DLA claims citing unfamiliarity with the new assessment criteria and the sheer volume of claims as the contributing factors.

From 1992 until the introduction of PIP, DLA was the main extra costs disability benefit for claimants of working age. Under DLA there was an emphasis on 'disablement' or 'severe disablement' (sections 72 and 73 of the Social Security Contributions and Benefits Act 1992). From April 2013 no new DLA claims could be made for adults of working age (hence the eligibility criteria is described in the past tense below) who must now claim PIP, although children under the age of 16 can still make applications. As we will see the tests for PIP are quite different and refer to the extent to which a person's physical or mental condition leads to a 'limited ability' to carry out a range of daily living or mobility activities. DLA had two components - care and mobility. The care component was payable at three different rates (high, middle and low) and the mobility component was paid at two rates (high and low). In order to qualify for the care component of DLA claimants needed to show that they needed attention with bodily functions or had supervision needs. The leading case on attention needs (Mallinson v Secretary of State for Social Security [1994], reported as R(A) 3/94) clarified that attention is in connection with a bodily function if it provides a substitute method of providing what 
the bodily function would provide if it were not totally or partially impaired. Attention involved personal contact from another person and was, therefore, active in nature. Alternatively, a claimant satisfied the supervision needs test if they needed more passive assistance (precautionary or anticipatory) in order to avoid substantial danger to themselves or others (section 72 (1) (b) Social Security Contribution and Benefits Act (SSCBA)1992). The reality of disabled claimants' lives meant that it was often difficult to accurately distinguish between attention and supervision needs and there was often overlap between the two tests.

DLA made a distinction between attention and supervision needs during the day and night with the high rate of the care component being awarded to those claimants who had either attention or supervision needs during the day and night and the middle rate for those claimants who needed attention or supervision during the day or night. The low rate of the care component picked up those claimants who needed attention for short periods during the day (known as a significant portion) and those who passed a theoretical test (commonly referred to as the 'cooking test') and could not through either physical or mental disability prepare a cooked main meal.

Eligibility for the high rate of the mobility component was reserved for claimants who were unable to walk or 'virtually unable to walk'. Arguably the test of virtual inability to walk was the most difficult for claimants, advisors and adjudication officers to assess and a very significant body of case law has amassed over the years in relation to this test. No distance was specified in the primary legislation but for professionals in the social welfare law sector 50 metres was considered to be the cut of point beyond which claims would normally fail (commissioner's decisions CDLA/608/1994 and CDLA/14594/1996 provide useful commentary on this issue). In order to qualify for the lower rate of the mobility component claimants needed to prove that they were so severely disabled that they could not mobilise outdoors in unfamiliar places without guidance or supervision from another person most of the time (section 73 (1) (d) SSCBA 1992). Unlike the high rate of the mobility component, which was aimed at claimants with physical health problems, the low rate of the mobility component was designed for claimants with mental health problems, sensory impairments or a learning disability.

The transition from DLA to PIP is underpinned by a change in perspective on who should qualify for working age disability benefits. The DWP stated (DWP, 2012a) that this change in philosophy was required as many DLA decisions were being made without reference to medical evidence, eligibility sometimes focused on the nature of a claimant's condition rather than the impact of the condition. Additionally, a perception existed that DLA is for claimants who cannot work, although the regulations allow for claimants to be in or out of work (DWP, 2012a). The DWP were aware that just over two-thirds of DLA claimants had an indefinite award of benefit (DWP, 2012a) and had a desire to introduce a system where there is a clear facility to regularly review awards (there are striking parallels with the Labour Government's rationale for replacing Incapacity Benefit with Employment and Support Allowance in 2008). The change in emphasis from the DLA language of 'disablement' and 'severe disablement' to the PIP terminology of 'limited ability' to carry out daily living or mobility activities consolidates this dominant change in philosophy that has pervaded the provision of welfare benefits for nearly a decade. Critics of this shift (Baumberg et al, 2015) have suggested that assessment of out of work benefits should be based on a 'real world -assessment' of claimant's health problems and cite The Netherlands and US as examples of countries where sophisticated databases of functional impairment are used to assess entitlement to benefit. This seems a distant 
prospect given the DWP's assertion in the PIP equality impact assessment that measuring each individual's expenditure would be administratively complex and expensive. (DWP, 2012a).

There remains two components under PIP, a daily living and a mobility component (section 77 (2) Welfare Reform Act 2012), a claimant may be awarded either or both of these components. Each of these components has two rates: a limited ability to carry out daily living or mobility activities results in an award of the standard rate and a severely limited ability attracts an award of the enhanced rate. The DLA process of self-assessment is replaced with a points based system assessed by a formal medical. The standard rate of either component is awarded if a claimant is awarded a minimum of 8 points and the enhanced rate is awarded if the claimant is awarded over 12 points.

The attention needs and/or supervision requirements under DLA have been replaced with a set of 10 different daily living activities. Under each activity there are a set of descriptors (or options) which represent varying degrees of ability. Different points are available for each of the descriptors (ranging from 0 to 12), the highest points from each of the descriptors that apply can be added together to give the claimant an overall score. Some claimants will be awarded PIP on the basis of a score of at least 8 points from one descriptor while other claimants will aggregate scores from a range of descriptors to reach the required threshold. The 'cooking test' which gave rise to the low rate of the care component has been preserved as daily living activity 1, although as discussed below it is not a straightforward replication of the DLA test.

The limited ability to walk or guidance/supervision outdoors of the DLA mobility component has been replaced under PIP with two mobility activities. Activity 1 considers the ability to plan and follow journeys (and has some similarities with DLA lower rate mobility) and activity 2 considers the ability to move around (and has some similarities with DLA high rate mobility).

For a descriptor to apply under either the daily living or mobility component a claimant must be able to complete the activity 'safely, to an acceptable standard, repeatedly and within a reasonable time period' (Regulation2- Social Security (Personal Independence Payment) (Amendment) Regulations 2013). A reasonable period of time is no more than twice as long as it would take an individual without disabilities to complete an activity. Unlike DLA, PIP does not make a distinction between day and night time needs and the default position is to make awards for a fixed period, although indefinite awards can be still be made.

Some of the key technical differences in the eligibility criteria between DLA and PIP and an analysis of those claimants who are likely to benefit or be disadvantaged by the transition is analysed below:

- Claimants who received the low rate of the mobility component of DLA on the basis of needing guidance or supervision when outdoors in unfamiliar areas may benefit from being recognised under activity 1 of the PIP mobility activities (planning and following journeys). This could lead to an entitlement of the enhanced rate of PIP on the basis of satisfying the 12-point descriptor under this activity 'cannot follow the route of a familiar journey without another person, an assistance dog or an orientation aid'. The risk for this group of DLA claimants is that they will miss out entirely on an award of the PIP mobility component if they are only judged to 'Need prompting to be able to undertake any journey to avoid overwhelming psychological distress to the claimant.' as this only brings an award of four points. There is already an emerging body of case law in relation to this issue. In [2015] 
UKUT 344 (ACC) Judge Jacobs supports a restrictive interpretation of this descriptor holding that it is irrelevant to consider help to overcome anxiety caused by other people and crowds. A broader interpretation is found in [2016] UKUT 531, which held that following a journey includes an ability to make progress and navigation.

- DLA high rate mobility claimants can be identified as potential losers. The 'unwritten rule' with DLA that an inability to walk more than 50 metres would lead to entitlement to the high rate of the mobility component has been removed. In order to qualify for the enhanced rate of the mobility component of PIP a claimant needs to prove that they can walk 20 metres or less. In July 2014 the High Court intervened on this issue dismissing a judicial review brought by a claimant who argued that the consultation in relation to the mobility activity was unlawful as it did not make explicit reference to the new 20 metre rule. Mr Justice Hickinbottom held that while the consultation had been 'mind-bogglingly opaque' it was not unlawful (Sumpter v the Secretary of State for Work and Pensions [2014] EWHC 2434 (Admin).

- Claimants who need assistance with budgeting may benefit from the introduction of PIP. Daily living activity 10 has three descriptors which attract points for problems 'making budgeting decisions'. It has been suggested that claimants who have an appointee to manage the administration of their benefits should be awarded 6 points under this new descriptor (Henry 2014).

- Similarly, claimants who require aids and appliances now have this taken into account under PIP. Under DLA many claimants perceived an unfairness that a reliance on aids and appliances could make an award less likely as this could be interpreted as evidence that the aid/appliance had removed the need for attention. Under PIP seven of the daily living activities (preparing food, taking nutrition, washing and bathing, managing toilet needs, dressing and undressing, communicating verbally, reading and understanding signs/symbols/words) include descriptors relating to the use of aids and appliances which attract 2 points, with a further descriptor allowing one point (managing therapy).

- Regulation 17 of the Personal Independence Payment (Transitional Provisions) Regulations 2013 provides that for those claimants who are transferring from DLA to PIP, the award of DLA continues for 28 days following the affirmative decision to award PIP. This will work to the advantage of claimants who will see a reduction in their entitlement when they move to PIP, but delay an increase in award where the reverse is the case.

- Claimants who have difficulty preparing a cooked main meal (previously covered by the low rate mobility of DLA under the 'cooking test') may have their award preserved under activity 1 of PIP daily living activities. 8 points is awarded under this descriptor for those who 'cannot prepare and cook food'. However, claimants with mental health problems who lack motivation to cook may miss out as the descriptor 'Needs prompting to be able to either prepare or cook a main meal' attracts only 2 points.

- Those claimants who previously received the middle rate of the care component of DLA on the basis of day-time attention needs may see an increase in an award of PIP to the enhanced rate of the daily living component (which makes no distinction between nighttime and day-time needs)

- Claimants entitled to the middle rate of DLA on basis of requiring supervision by day or watching over at night may find it difficult to secure a comparable award of PIP. Five of the PIP daily living activities include descriptors for supervision (preparing food, taking nutrition, 
managing therapy or monitoring a health condition, washing and bathing and managing toilet needs or incontinence). However, the majority of these descriptors attract only 2 points. This could have a particularly negative impact on claimants with mental health problems.

\section{The Gray Review of the Personal Independence Payment assessment}

The WRA 2012 (section 89) requires the Secretary of State to commission two independent reviews of the effectiveness of the PIP assessment process. In 2014 Paul Gray was appointed as independent reviewer of the PIP assessment. An independent scrutiny group was appointed with five representatives from a range of backgrounds including academia and disability organisations. The review used a mixed methodology approach to gather evidence. This included a review of social security statistics, a call for evidence (which received over 800 responses), interviews with claimants and staff from the DWP, meetings with ATOS and Capita (the contracted assessment providers) and an interview with a Regional Tribunal Judge.

In the foreword to the review Gray acknowledged the challenges associated with the adjudication process for a disability benefit stating that 'functional assessment is not a precise science' (Gray, 2014, p.2). He alluded to a complex range of factors including physiological, psychological, motivational and social, that impact on a claimant's daily life. To emphasise the enormity of the task he highlighted not only that the design of PIP is being undertaken against the backdrop of austerity, but also that few other counties attempt a similar system where entitlement is based on an individual assessment of disability. Without question attempts to reform the disability benefits system and at the same time make significant savings to the social security budget are challenging. The Organisation for Economic Cooperation and Development (OECD, 2014) state that in an economic recession social spending-to-GDP ratios normally increase as government spending rises to meet a greater need for social support. However, the UK is in a minority of OECD countries which have responded to the economic downturn by reducing social spending as a ratio of GDP. This balance between rationalising public spending and protecting and promoting the rights of disabled citizens has been described by Jordan (2006, p.40) as 'optimum security' which 'involves looking at what measures can give people opportunities to develop their capabilities, while leaving them free to take up these opportunities in their own way.'

The Gray review made recommendations in three main areas: improving the claimant experience, improving the collection of further evidence and assuring the fairness and consistency of the assessment.

\section{Improving the claimant experience}

When considering the claimant experience the Gray review focused on the claimant journey from the initial claim through to decision making. The principal concerns identified were that communication with claimants is often inconsistent, advice provided to claimants can be incomplete, communication between the DWP and contracted assessment providers is disjointed and that significant improvements need to be made to DWP case management systems.

Without doubt the most publicised criticism of PIP has been the delays in decision making. The Review reported (p. 32) that many claimants feel that delays in the assessment process lead not only 
to anxiety but also a deterioration in the health condition for which they are claiming benefit. Concerns were expressed that the two stage claims process (an initial telephone call to the DWP, followed by the completion of a paper based form) contributes to delays. It was reported that the first stage of this process could be particularly problematic for claimants with mental health problems, hearing difficulties or learning disabilities. Advice agencies (notably Mencap and Parkinson's UK) reported difficulties when contacting the DWP to support claimants. This is despite 'implicit consent arrangements' which should allow trusted intermediaries to liaise with the DWP (DWP, 2009). Evidence provided on the paper form itself was mixed, with some respondents believing it to be an improvement on the previous Disability Living Allowance form but many expressing concern that a one-month deadline to return the form is too short.

In relation to the significant problem of delays Gray made a long-term recommendation that an improved operating model is required which utilises digital technology, moves away from a 'one size fits all' approach and allows claimants to track the status of their claim. In accepting this recommendation, the Government state that they have developed an improved PIP digital claim which streamlines the previously disjointed process and keeps claimants (and/or their representatives) informed of progress through SMS texting.

Given that there is no legal requirement for the DWP to make a PIP entitlement decision within a specified time Child Poverty Action Group (CPAG) have suggested that claimant representatives should consider pursuing a formal complaint to the DWP (and the assessment provider), pursue a complaint through a member of parliament, or consider a judicial review application (Shaw, 2014). Additionally, the DWP's Special Payment Scheme does allow for ex-gratia payments where there is evidence of maladministration, including unreasonable delay (DWP, 2012b).

Redress through the courts remains an option for claimants experiencing the type of delays identified by the Gray Review. In C \& Anor, R (on the application of) v Secretary of State for Work and Pensions \& Anor [2015] EWHC 1607 (Admin) it was held that delays in the PIP decision making process were unacceptable and unlawful. The two claimants challenged the legality of the processing of PIP arguing that it breached the duty on the part of the defendant to act within a reasonable time, and breached Article 1 (right to peaceful enjoyment of possessions) and Article 6 (right to a fair hearing within a reasonable time) of the European Convention on Human Rights (ECHR). In handing down her judgment Mrs Justice Patterson found that the claimant's human rights had not been breached but the delays in the determination of benefit entitlement (thirteen months for the first claimant and ten months for the second claimant) were unlawful. She acknowledged the challenges associated with the roll-out of PIP, however, the administrative and processing delays in the cases of $\mathrm{C}$ and $\mathrm{W}$ were found to be so significant that they inhibited the ability of vulnerable claimants to access payment. Whilst the significance of this decision should not be downplayed Mrs Justice Patterson made it clear that the claimants' cases should not be treated as test cases.

\section{Improving the collection of further evidence}

The Gray Review emphasised the importance of the collection of further evidence to ensure accurate and timely decisions are made. Further evidence can be collected from a wide range of parties (for example claimants, GPs, consultants, social care professionals) and starts when a claimant makes initial telephone contact with the DWP.

One of the Review's main recommendations in this area was that evidence/information held elsewhere should be used for the PIP assessment process (subject to appropriate data protection 
protocols). The most obvious example of this is to consider evidence held by the DWP in relation to another benefit claim (e.g. Employment and Support Allowance) but could extend more broadly to information held by other parts of the public sector. This theme was evident in the call for evidence with some claimants expressing confusion as to why they were required to attend multiple medical assessments for more than one benefit when they appeared to deal with similar issues.

Perhaps unsurprisingly the Government accepted the Reviews' recommendations in relation to extending the sharing of information, stating that they would explore the appropriateness of using information from different DWP assessments. The Government acknowledged that many disability organisations have concerns about extended data sharing arrangements, which could lead to reduced entitlements for some claimants. However, movement is certainly towards a greater degree of data sharing as the Government consider using not only information held by the DWP, but also looking at information gathered by social services, and the Department of Health.

These data sharing considerations are not a new development in the social welfare law sector. The appropriateness of data sharing has been an issue for professionals, decision makers and judges for many years. The DWP's internal guidance for decision makers 'Principles of Decision Making and Evidence' (DWP, 2013) does provide advice which is entirely consistent with Gray's recommendations. It instructs decision makers to exercise a level of caution when considering whether evidence obtained for one benefit should be considered as reliable when considering entitlement to other benefits:

DMs should bear in mind that medical reports are produced in order to determine whether the person satisfies the conditions of entitlement for a particular benefit and that some of the findings might not be relevant to another benefit. For example, where a WCA report is used as evidence to disallow an award of ESA or credits, and the decision is overturned on appeal, the WCA report may not be a useful source of evidence when deciding a claim for PIP." (paragraphs A1570 and A1573)

This issue was the subject of a significant number of decisions by Social Security Commissioners when considering appeals brought against Disability Living Allowance claims. Claimants have a right of appeal against a decision made by the first-tier tribunal. Before November 2008 appeals were made to Social Security Commissioners. Since this date Social Security Commissioners have formed part of the Upper Tribunal which deals with appeals brought against a first-tier tribunal on the basis of an error of law. Upper Tribunal decisions dealing with PIP appeals are not bound by previous DLA decisions and, therefore, tell us much about the different ways in which disability is now interpreted and assessed. A good example of this can be seen in JC V SSWP [2015] UKUT 0144 where it was held that when considering the variability of care needs the long established Moyna test in DLA cases ( $R(D L A) 7 / 03$ ) has no place in PIP decisions as this issue is now covered by Regulation 7 of the PIP regulations. In Moyna the House of Lords held that the assessment of care needs should involve a broad assessment of disability over a period of time. Rejecting this approach for PIP, Judge Gamble emphasised that a scoring descriptor applies to claimants where their impairment affects their ability to complete an activity on more than $50 \%$ of days in a twelve-month period.

The Personal Independence Payment Regulations do not appear to make such a clear move away from DLA when it comes to further or supporting evidence. Part 2 of the regulations (section 8) sets out the 'Information or evidence required for determining limited or severely limited ability to carry 
out activities'. This provision is very general in scope and merely stipulates that the claimant must provide information or evidence to the Secretary of State as requested within a reasonable period of time (usually within one month). It follows that previous DLA Upper Tribunal decisions in relation to data sharing and provision of evidence remain apposite. Upper Tribunals (see for example CDLA/5803/1999*) generally found that information from incapacity benefit/employment support allowance medicals could be used for DLA purposes providing the evidence was 'properly comparable'. CDLA/2710/2011 held that tribunals should take a consistent approach when considering evidence from other benefits and CDLA/3896/2006 emphasised the dangers in extrapolating evidence obtained for one disability benefit and applying it to the eligibility criteria for another. The submissions to the Gray Review, by both advice agencies and claimants, illustrated that there isn't a consensus on the appropriateness of data sharing, it remains open to debate whether the availability of increased evidence leads to fairer or more accurate decision making.

The Gray Review called for clarity about the purpose of PIP face-to-face assessments. The Review found that there remains a perception, often by claimants but also by advice agencies, that the PIP assessment is a medical rather than an assessment of functional ability as laid out in the legislation. This has a significant impact on the collection of further evidence as claimants will often seek medical reports from their GP or consultant. The Gray Review recommended that in the mediumterm the DWP should explore opportunities to improve the collection of further evidence and provide greater clarity about evidence required and who is responsible for gathering the evidence. Decisions makers reported that claimants can sometimes provide large amounts of information which is deemed to be irrelevant (e.g. hospital appointment letters) and that this places an unnecessary administrative burden on staff.

\section{Assuring fairness and consistency of PIP award outcomes}

This part of the Gray Review examined some fundamental questions about the extent to which PIP can provide appropriate, targeted support for some of the most vulnerable people in society, while at the same time delivering value for the money for the tax payer. Academics, social welfare law agencies and disability campaigning groups should welcome Gray's recommendation that the DWP should put in place a rigorous quantitative and qualitative evaluation strategy, with a particular focus on the appropriateness of PIP assessments for people with a learning disability or mental health problem. One such organisation may be the British Psychological Society (BPS, 2016) which following a Channel 4 Dispatches programme (Channel 4 Dispatches: The Great Benefits Row, 2016) expressed concern that the PIP assessment process adopts a formulaic approach which does not recognise the highly individualised nature of mental health problems. Gray drew attention to the limitations in the quality assurance and audit systems used by the DWP, arguing that the process of 'vertical scrutiny' i.e. an analysis of individual PIP assessments currently used, should be complemented by 'horizontal scrutiny' which would take a large representative sample from across different regions in the county.

This section of the Gray Review made specific recommendations in relation to aids and appliances and planning and following journeys. The Review's evidence on aids (devices that help performance of a function, for example walking sticks) and appliances (devices that provide or replace a missing function, for example wheelchairs) was used to justify the government's aborted proposals to make significant cuts to the Personal Independence Payment budget. The Review stated that there were 
indications that claimants were being awarded points as part of the PIP assessment process for needing aids or appliances, but in reality through choice and not medical need claimants are making these purchase themselves, often at a very lost cost. This is significant as the awarding of points for requiring aids and appliances can be a key determining factor in a claimant meeting the threshold for an award of PIP. The Review recommended that the government review how aids and appliances are accounted for in the assessment process and consider adjustments to guidance and staff training.

Following public consultation (DWP, 2015a), the government decided that the points awarded for the need to use aids and appliances in relation to the dressing and undressing and managing toilet needs activities in the PIP assessment would be halved from two to one. The government's justification for this decision was twofold. Firstly, it was judged that these activities could not be seen as being reasonably associated with extra costs. Secondly, following the Gray Review the DWP undertook a case-load review and concluded that many of the aids and appliances used by claimants are 'provided free of charge by the NHS and local authorities or can be purchased for a low one-off cost'. (DWP, 2016b, p. 4).

The Institute for Fiscal Studies (IFS, 2016) estimated that 370,000 claimants would be affected by these changes to the dressing/undressing and managing toilet needs descriptors, either seeing a reduction or loss of award, producing government savings of $£ 4.4$ billion by $2020-21$. The government announced the above changes in the budget of 2016 and presumably expected a backlash from disability organisations but were perhaps surprised by the level of public opposition. A YouGov poll found $70 \%$ of the public believed the cuts to PIP for people who need to use aids and appliances were the wrong priority, with only $13 \%$ judging them to be a good idea (YouGov, 2016). In his resignation letter (BBC, 2016) following the budget lain Duncan Smith stated that reductions in PIP 'are not defensible in the way they were placed within a Budget that benefits higher earning taxpayers. They should have instead been part of a wider process to engage others in finding the best way to better focus resource.' Less than a week after the budget the new work and pensions Secretary Stephen Crabb announced that the reversal of the proposed cuts (Hansard, 21 March 2016, col 1268).

The significance of the Gray Review cannot be understated. It should not only be viewed as a statutory requirement to audit the adjudication of PIP. It also galvanised claimants and campaigning groups who saw this as an opportunity to raise grievances. For the Government the findings have been used to propose policy changes - although as the resignation of lain Duncan attests, this is a strategy that comes with some risk. The issues considered by the Review will remain of importance in the years ahead as we see the full implications of the transition from DLA to PIP for working age claimants. The second Gray Review, due to be published in 2017, will focus on further evidence, data sharing and further scrutinise the claimant experience (DWP 2016a). 


\section{UN Committee on the Rights of Persons with Disabilities}

This article has explored the transition from DLA to PIP and the influence of the Gray Review. Scrutiny is also being applied to the disability benefits system from outside the UK. Campaigning by disability charities, such as Disabled People Against Cuts (DPAC), influenced the decision of the UN Committee on the Rights of Persons with Disabilities to conduct an inquiry into the impact of the UK Government's policies on disabled people (Poliowski, 2016). Since 2007 the UK has been a signatory to the Optional Protocol to the Convention on the Rights of Persons with Disabilities. The Convention is an international human rights treaty adopted by the UN General Assembly in 2006 and promotes and qualifies the rights of disabled people as defined by the Universal Declaration of Human Rights. The Optional Protocol gives power to the UN Committee to conduct an investigation if they have credible evidence of 'grave and systematic violations of the Convention'. The UK is the first country to be investigated under this Convention. The findings in relation to disability benefits (including PIP) are significant, although the Government has no legal obligation to act upon them.

\section{Background to the Inquiry and compliance with Article $\mathbf{2 8}$ of the Convention}

The Committee on the Rights of Persons with Disability confirmed that they started to receive information in 2012 which alleged that the government's social security policy was having an adverse impact on disabled people and was affecting the rights enshrined in the Convention. In April 2013 the Committee agreed to register the request for an Inquiry and the Government submitted formal responses to the inquiry on 20 August 2013 and 28 March 2014. In April 2014 the Committee assessed that there was reliable information indicating grave or systematic violations of the Convention. A closed hearing commenced in London in October 2015 with the media reporting (Butler, 2016) that the hearing lasted for 11 days taking evidence from more than 200 individuals including MPs, activists and academics. It is understood that two UN envoys heard additional witness statements in Manchester, Bristol, Scotland, Northern Ireland and Wales. The UN published the findings of their inquiry (UN, 2016) in October 2016 and the Government's official response was published the following month (UK Government, 2016).

In relation to disability benefits the Committee considered the UK Government's compliance with three specific articles of the Convention: Article 19 (Living independently and being included in the community), Article 27 (Work and employment) and Article 28 (Adequate standard of living and social protection). All three Articles are of significance to the administration of disability benefits, but Article 28 has the clearest synergies stating:

This article affirms the rights of persons with disabilities to an adequate standard of living for themselves and their family, and to social protection without discrimination on the basis of disability. This right includes access to assistance from the state with disability-related expenses for persons with disabilities and their families

Under Article 28 social protection is defined as interventions designed to guarantee basic income security such as poverty reduction programmes. Article 28 emphasises the need to provide access to mainstream services through the provision of social security benefits which acknowledge disability related needs and expenses and highlights that disabled people are disproportionately affected by poverty and should be meaningfully protected by social security systems.

There are well established links between health inequalities and income inequalities (Rowlingson 2011, Wilkinson and Pickett 2010). The Department for Work and Pensions argue that PIP will help to ameliorate these inequalities by providing financial support to enable disabled people to live 
more independent and active lives (DWP, 2012a). There are a number of significant political and economic factors at play which may limit the likelihood of these aims being achieved. The Social Mobility and Child Poverty Commission (SMPCP, 2015) found that people experiencing persistent poverty (having less than 60 per cent of current median income for at least three of the previous four years) are often living with a long-term disability or illness. DWP statistics for 2013/14 illustrate the reliance that disabled people in the UK have on social security benefits. $83 \%$ of families with at least one disabled adult in the household were in receipt of state benefits. The reliance on state support is even greater where there is a disabled child in the household with $95 \%$ of families claiming a state benefit (DWP, 2016c). Critics may suggest that as the roll out of PIP is expected to result in 607,000 (DWP, 2012a) fewer claimants than under the previous DLA regime, government policy is directly contributing to health and income inequalities.

Compliance with Article 28 requires eligibility criteria for 'social programmes' to take into the social model of disability and not the medical model 'addressing the multiple barriers that limit the participation of persons with disabilities in society, and not rely on narrowly defined medical criteria or medical assessments.' (UN 2016, p.6). The move from DLA to PIP was an opportunity for a fundamental revaluation of how the state interprets disability. The eligibility criteria for any social security benefit by definition produces a framework where claimants are assessed as either 'included' or 'excluded'. The social model of disability as developed by Oliver (1983) argues that disability should not be defined by impairment but by the disabling barriers created by society. The introduction of DLA was accompanied by academic debate about the extent to which this new benefit embraced the social model of disability. Noble, Platt, Smith and Daly (1997) argued that the assessment of DLA was more closely aligned with the medical model of disability, with disability being viewed as a property of the disabled person. The introduction of PIP has introduced many significant changes but has done little to reverse the association with the medical model of disability. Roulstone $(2015$, p.14) believes that it is inappropriate for disability benefit reforms to embrace an assessment that focuses on the minutiae of how the body works and argues that 'A social model response would suggest these new formulations are unhelpful and fail to account for social barriers'.

The Inquiry emphasised that Article 28 dictates that social security programmes should be adapted to the needs of people with disabilities and provide benefits at an adequate level for claimants to enjoy an adequate standard of living. Fitzpatrick (2011) emphasises that policy makers have often been reluctant to embrace the social model as it is assumed to be associated with high costs. He argues that disabled people have not been served well by the benefit system, which fails to adequately meet the additional costs of disability: 'If future welfare reforms are to be effective, then they must be underpinned by strong and comprehensive legislation that emphasizes the social rights of disabled people' (Fitzpatrick, 2011, p.167). Duffy (2014) found that recent government policy has not met the aspirations set out by Fitzpatrick with public sector cuts, including welfare reform, reductions in legal aid and cuts in local government budgets, resulting in disabled people losing an average of $£ 4,660$ per year (disabled people make up $4 \%$ of the population but bear $13 \%$ of public sector cuts).

Finally, in relation to Article 28 member states should provide information in relation to disability benefits which is accessible, eligibility criteria should be 'proportionate and transparent' and 'consultation processes should not be merely symbolic' (UN 2016, p. 6). 


\section{Findings and recommendations of the Inquiry}

The Inquiry made a range of general findings in relation to the Government's welfare reform policy. The initial findings provide a commentary on the aims of the Government's welfare reform policy and fiscal deficit programme. The government have been explicit in their policy aims (Kennedy, 2015) and it would appear likely that the government would defend the right to make these cuts however unpalatable they are to some sections of the electorate. In broad terms the government have a mandate to make significant cuts to the welfare budget, although the Conservative Party manifesto pledged to exempt disability and pensioner benefits from cuts (Conservative Party, 2015).

A more contested finding of the Inquiry relates not to the aims of welfare reform but with its consequences. As we have seen the Government asserts that the move from DLA to PIP was required to ensure that support is focused on those with greatest need and expenditure was placed on a more sustainable footing (DWP 2012a). However, the Inquiry found there to be an inherent contradiction in the aims of these reforms. The pre-implementation assumption that a significant percentage of disabled people would no longer rely on disability benefits was predicated on the fact that only those with low or moderate needs would be affected. However, the Inquiry found that many of those disabled people with supposed lower level of needs have been affected not only by the move from DLA to PIP but also by changes made elsewhere in the benefit system (for example, reductions in housing benefit, the benefit cap) and by the closure of the Independent Living Fund. The cumulative impact of these changes was found to create vulnerabilities which the social security system should be seeking to alleviate. Taken as a whole the Inquiry found that welfare reform has disproportionally affected people with disabilities. Evidence was presented to indicate that many disabled people have seen a reduction in incomes, an increased dependency on informal and family care, increased stress and a reliance on discretionary services, including food banks (UN 2016, p.19).

The Inquiry found that information, advice and guidance for disabled people about their rights to disability benefits was limited or non-existent. Concerns were raised about information not being provided in appropriate formats and languages and that this causes unnecessary barriers to entitlement and often anxiety for potential claimants. The Inquiry made findings in relation to the mandatory reconsideration (MR) procedure, stating that this new process has curtailed access to first-tier tribunals. MR was introduced in April 2013 for Personal Independence Payment and Universal Credit claims, and in October 2013 was extended to claims for all other DWP benefits (section 102 of the Welfare Reform Act 2012 and the Universal Credit, Personal Independence Payment, Jobseeker's Allowance and Employment Support Allowance (Decisions and Appeals) Regulations 2013). Before the introduction of MR claimants wishing to challenge a DWP decision could lodge an appeal directly with Her Majesty's Courts and Tribunals Service (HMCTS) and pursue their appeal to an independent first-tier tribunal. The first-tier tribunal (Social Security and Child Support) are responsible for hearing appeals against decisions relating to all DWP benefits. Under the MR process claimants must ask the DWP to reconsider their decision during the 'dispute period' of one month. An appeal to the first-tier tribunal can only be pursued once the DWP have issued a MR decision. There are no statutory time limits that stipulate how long the DWP should take to reconsider decisions under this process. The DWP (2013) stated that a new procedure for challenging benefit decisions was needed to ensure the earliest possible resolution of disputes and to reduce the burden on HMCTS. Amongst critics of the new system was His Honour Judge Robert Martin, formerly the President of Social Entitlement Chamber of the First-tier Tribunal. The House of Commons Work and Pensions Committee (2014) reported that he believed that the introduction of MR was a 'dubious advantage' as claimants now have to make two applications (MR and appeal to 
HMTCS) before an appeal is heard by a tribunal. Furthermore, he raised concerns that the reduced burdens on tribunals would be as a result of claimants not pursuing legitimate appeal cases as the system has become too onerous and convoluted.

The Inquiry noted that the Government have made formal efforts to improve the image of disabled people but were concerned that recent policy developments have led to a negative portrayal of disabled benefit claimants in the media and that this has influenced public opinion. There is a growing body of academic evidence that analyses the above phenomenon: Garthwaite (2011) has analysed the language of 'shirkers and scroungers' finding parallels between recent depictions of disabled claimants with the classification of 'deserving' and 'underserving' poor at the inception of the welfare state. She described the process of 'othering' where benefit claimants are often singled out as lazy, workshy or cheats. Roulstone (2015) believes that there are fundamental links between government policy and the way that disabled claimants are portrayed in the print and television media. Justifications for changes in policy are pushed through on the back of binary representations of people as being either 'legitimate' or 'non-legitimate' disabled people. He states that the classification of disability is often redefined in periods of financial uncertainty with 'the use of media and cultural sources to back up the political project' (Roulstone, 2015, p13). Perhaps most damagingly Roulstone identifies that current reforms to disability benefits use the language of independence to justify changes that in reality undermine the rights of disabled people.

As described earlier the PIP claimant journey was closely scrutinised by the Gray Review and the UN Inquiry also raised concerns about the experiences of claimants who 'felt that they were merely processed rather than being listened to or understood' (UN 2016, p.16). The Inquiry accepted that steps are being taken to improve PIP service delivery (in response to the Gray Review's recommendations) but raised particular concerns that claimants requiring high levels of support, such as those with psychosocial difficulties, were not having their views and personal history properly accounted for by decision makers. The concerns described in the section above by academics in the Disability Studies field that the PIP assessment process is closely aligned with the medical model of disability were shared by the Inquiry. Concerns were raised that there is a lack of focus on the support that people with disabilities need and the barriers that they face. The Inquiry concluded that the Government failed to carry out adequate equality impact assessments to assess the impact of the WRA 2012 and, therefore, failed to comply with domestic equality duties.

In light of the above findings the Inquiry concluded that 'there is reliable evidence that the threshold of grave or systematic violations of the rights of persons with disabilities has been met in the State party' and that Government policy has had an 'adverse and disproportionate effect on persons with disabilities' (UN 2016, p.20). The Inquiry made eleven recommendations, five of which are directly related to the administration of disability benefits:

- The Inquiry recommended that the Government should measure the impact of welfare reform on disabled people by carrying out a cumulative, human-rights based equality impact assessment.

- With direct links to the findings of the Gray Review, the Inquiry stated that the Government should improve the administration of social security benefits and make the social security system more accessible for disabled people.

- The Government are urged to ensure that access to justice for disabled people is improved and appropriate legal advice and support is provided for disabled people seeking to challenge decisions.

- It is recommended that the Government take appropriate steps to consult with disabled people and their representatives to 'give due consideration to their views in the design, 
implementation, monitoring and evaluation of any legislation, policy or programme action related to the rights addressed in the present report' (UN 2016, p. 21).

- Finally, it was recommended that steps should be taken to challenge negative stereotypes about people with disabilities in the media and wider public with particular emphasis placed on the need to challenge the widely held perception that benefit dependency is, in itself, a disincentive to find work.

\section{Government's response to the Inquiry}

The UK Government strongly disagrees with the findings of the UN Inquiry and does not accept that there is evidence of grave and systematic violations of the rights of disabled people (UK Government, 2016). In a robust defence of their record the Government's official response to the UN Inquiry cites a combination of legislative provision, official statistics and policy that they believe demonstrates a strong record of supporting disabled people.

In relation to PIP the Government reassert their positon that DLA was a flawed system that was in need of fundamental reform. They believe that there is an unnecessary retrospective focus on DLA as this was a benefit that did not meet the needs of disabled claimants or provide value for money. The Government state that a comparative exercise examining the relative merits of DLA and PIP is inappropriate and that rather than raising the threshold of eligibility PIP is better targeted to the needs of the current population.

The Government cite statistics (DWP, 2016c) which they believe demonstrate the appropriateness of PIP but which also provide an interesting summary of the early progress of this benefit. A significant number of people who move from DLA to PIP receive a higher award, with $24 \%$ of PIP claimants receiving both components at the enhanced rate compared to $15 \%$ of claimants who received the high rate of both components of DLA. The Government argue that PIP provides a more equal footing for physical and mental health. As a result, $24 \%$ of PIP claimants with a mental health condition receive the enhanced rate of the mobility component, compared to only $9 \%$ who received the high rate mobility DLA. Similarly, $66 \%$ of PIP claimants with mental health problems receive the enhanced rate of the daily living component compared to $22 \%$ for the DLA equivalent (UK Government 2016, p.24). The Government believe that in accepting many of the recommendations of the Gray Review they have effectively pre-empted some of the issues raised by the UN Inquiry. On the initially problematic issue of waiting times for a PIP decision the Government state that this is now under control with an average wait of 7 weeks for a decision (UK Government 2016, p24). The Government also claim that communications with claimants has improved following a complete re-write of letters and other communication products.

An assessment of the strength and validity of the Government's response to the UN Inquiry ultimately brings us to fundamental questions about how disability should be categorised and the extent to which the state should support disabled claimants. The Government point to statistics on social security expenditure which demonstrate a $f 50$ billion spend per year on benefits to support people with disabilities, over $f 6$ billion more than in 2010 . Amounting to over $6 \%$ of expenditure the Government believe that the UK compares favourably with the OECD average and countries such as Germany, France and the USA. This perhaps only provides a partial representation of the fiscal position as the Institute for Fiscal Studies (2014) state that welfare reform is associated with 'the largest real reductions in expenditure in history'. Hills (2015) emphasises that over the course of the coalition government's period in office (2010-2015) working age people with lower incomes were net losers as a result of the full combination of benefit and tax credit changes. Many PIP claimants will fall into this category. 
The Government believe that the UN Inquiry had too narrow a scope and a focus on welfare reform neglected to acknowledge spending commitments in other areas which promote the rights of disabled people such as personal budgets and improved access to transport. Critics argue that the Government's record in supporting disabled people actually becomes far worse when a broader view is taken. Duffy (2013) argues that disabled people are particularly damaged by government cuts to benefits and local government, which account for over $50 \%$ of overall savings. The Government's response to the UN Inquiry emphasised that aggressive and/or discriminatory behaviour towards disabled people is unacceptable but made no reference to the role of the media in perpetuating stereotypes about disabled claimants.

\section{Conclusion}

In response to the Gray Review the Government have made some changes to the assessment and adjudication processes of PIP, although the eligibility criteria remains unchanged. In spite of the criticisms of PIP made by the UN Inquiry on the Rights of Persons with Disabilities the short-term future of this disability benefit seems secure. In the longer-term political, fiscal, and legal factors will influence the level and assessment of this payment which is seen as essential for many disabled people. Reform of any social security benefit will rightly draw scrutiny and undoubtedly lead to criticism from some quarters. Harris (2015) has analysed the problems that can be associated with a complex social security system including lack of understanding by claimants, low take-up of benefits by those who may be entitled, high administration costs and administrative errors. However, he also identifies justifications for complexity, for example, allowing for a high level of differentiation between similar claims and encouraging consistency. This article has demonstrated that these tensions are particularly pertinent to the administration of PIP and as Harris $(2015$, p. 218$)$ states 'Simple rules may be easier to administer but they are likely to offer a less sophisticated basis for responding to specific social problems and needs.'

The phrase 'claimant journey' has become part of the social security benefits lexicon but as this article has explored the direct experiences of a claimant are only one element of a longer and more complex process. The process begins with the setting of a government's legislative programme. Once social security legislation is enacted practical adjudicating matters take hold and we can see how individual decision making, and in the case of PIP, provision of evidence from a wide and often conflicting range of sources becomes the influencing factor in determining benefit entitlement. The Gray Review justifiably focused on the role of private assessment providers. Many organisations who responded to the call for evidence argued that these companies exhibit a lack of accountability and quality control, while at the same time exerting a very significant level of influence over the decision making process. In 2015/16 60\% of PIP appeals heard at first-tier tribunal led to a reversal of the initial decision made by the DWP, with new oral or documentary evidence provided being the lead reason for $75 \%$ of these overturned decisions (Parliamentary written question 37130,2016 ). While this remains the case claimant representatives and first tier and upper tribunal social security judges will remain key players in holding the system to account. Section 94 of the WRA 2012 allows the Secretary of State to make incidental, supplementary or consequential changes to the benefits introduced under the welfare reform agenda. While a clear legislative path is available to make changes to PIP, this article has highlighted that making amendments to social security benefits is rarely a straightforward process. 


\section{References}

Baumberg, B., Warren, J., Garthwaite, K., Bambra,C. (DEMOS 2015). Rethinking the Work Capability Assessment. Retrieved from: https://www.demos.co.uk/files/Rethinking - web 1 .pdf?1426175121

BBC. (2016). In full: lain Duncan Smith resignation letter. Retrieved from:

http://www.bbc.co.uk/news/uk-politics-35848891

British Psychological Society. (2016). Disability assessors must be properly assessed says BPS.

Retrieved from: http://www.bps.org.uk/news/disability-assessors-must-be-properly-trained-saysbps-after-channel-4-dispatches-programme

Butchins, R. (2016). The Great Benefits Row [Televison series episode]. In Boulton, S. (Executive Producer), Dispatches. London: Channel 4

Butler, P. (2016). UK austerity policies 'amount to violations of disabled people's rights'. Retrieved from https://www.theguardian.com/business/2016/nov/07/uk-austerity-policies-amount-toviolations-of-disabled-peoples-rights

Child Poverty Action Group. (2016) Welfare benefits and tax credits handbook. London: Child Poverty Action Group

Conservative Party. (2015). Conservative Party Manifesto. Strong Leadership, a clear economic plan, a brighter, more secure future. Retrieved from:

https://www.bond.org.uk/data/files/Blog/ConservativeManifesto2015.pdf

Daly, D and Noble, M. (1996). The reach of disability benefits: an examination of the disability living allowance. Journal of Social Welfare and Family Law (18) (1) 1996 37-51

Department for Social Security (1990). The Way Ahead - Benefits for Disabled People. London. HMSO

Duffy, S. (2013). A Fair Society? How Cuts Target Disabled People. Retrieved from: http://www.centreforwelfarereform.org/library/type/pdfs/a-fair-society1.html

Duffy, S. (2014). Counting the Cuts. What the government doesn't want the public to know. Retrieved from http://www.centreforwelfarereform.org/news/counting-thert-published/00141.html.

DWP. (2009). Working with representatives: guidance for DWP staff. Retrieved from:

https://www.gov.uk/government/publications/working-with-representatives-guidance-for-dwp-staff

DWP.(2012a). Disability Living Allowance Reform. Equality Impact Assessment May 2012. Retrieved from https://www.gov.uk/government/uploads/system/uploads/attachment_data/file/220151/eiadla-reform-wr2011.pdf

DWP. (2012b). Financial redress for maladministration: staff guide. Retrieved from:

https://www.gov.uk/government/uploads/system/uploads/attachment data/file/422425/financialredress-maladministration-apr-15.pdf 
DWP. (2013). DMG Vol 1. Principles of decision making and evidence. Retrieved from:

https://www.gov.uk/government/publications/decision-makers-guide-vol-1-decision-making-andappeals-staff-guide

DWP. (2015a). Consultation on aids and appliances and the daily living component of Personal Independence Payment. Retrieved from:

https://www.gov.uk/government/uploads/system/uploads/attachment data/file/484217/pipconsultation-on-aids-and-appliances.pdf

DWP. (2015b). Benefit expenditure and caseload tables 2015. Historic and forecast benefit expenditure and caseload data for people receiving benefits. Retrieved from:

https://www.gov.uk/government/statistics/benefit-expenditure-and-caseload-tables-2015

DWP. (2015c). Personal Independence Payment (PIP) assessments first independent review: government response. Retrieved from:

https://www.gov.uk/government/uploads/system/uploads/attachment data/file/407581/pipassessment-first-independent-review-response.pdf

DWP (2016a). Personal Independence Payment (PIP) assessment: second independent review call for evidence. Retrieved from: https://www.gov.uk/government/consultations/personal-independencepayment-pip-assessment-second-independent-review-call-for-evidence

DWP. (2016b). The Government response to the consultation on aids and appliances and the daily living component of Personal Independence Payment. Retrieved from:

https://www.gov.uk/government/uploads/system/uploads/attachment data/file/507166/governm ent-response-aids-and-appliances-and-the-daily-living-component-of-pip.pdf

DWP. (2016c). Personal Independence Payment: Official Statistics to January 2016. Retrieved from: https://www.gov.uk/government/uploads/system/uploads/attachment data/file/506734/pipstatistics-to-jan-2016.pdf

Fitzpatrick, T. (2011). Welfare Theory - an introduction to the theoretical debates in Social Policy. Basingstoke: Macmillan.

Garthwaite, K. (2011). 'The language of shirkers and scroungers?' Talking about illness, disability and coalition welfare reform. Disability \& Society, 26:3, 369-372, DOI: 10.1080/09687599.2011.560420

Gray, P. (2014). An Independent Review of the Personal Independence Payment Assessment. London: HMSO. Retrieved from https://www.gov.uk/government/publications/personal-independencepayment-pip-assessments-first-independent-review

Hansard. (2016). HC Debate. Vol. 607, Col 1268, 21 March 2016.

Harris, N. (2014). Welfare Reform and the Shifting Threshold of Support for Disabled People. The Modern Law Review, 77(6), 888-927

Harris, N. (2015). Complexity in the law and administration of social security: is it really a problem? Journal of Social Welfare and Family Law, 37:2, 209-227, doi: 10.1080/09649069.2015.1028155 
Henry, J. (2014) Early experiences of personal independence payment. Journal of Poverty and Social Justice, volume 23, number 3, doi.org/10.1332/175982714X14113978361426

Hills, J. Centre for the Analysis of Social Exclusion (2015). The Coalition's Social Policy Record 20102015. Retrieved from: http://sticerd.Ise.ac.uk/dps/case/spcc/RR04 SUMMARY.pdf

House of Commons Social Security Committee (1993). Disability Benefits: The Delivery of Disability Living Allowance and Disability Working Allowance. London:HMSO

House of Commons Work and Pensions Committee (2014). Mandatory reconsiderations and appeals. Retrieved from:

http://www.publications.parliament.uk/pa/cm201415/cmselect/cmworpen/302/30209.htm

IFS. (2014). A Survey of the GB Benefit System. Retrieved from:

https://www.ifs.org.uk/uploads/publications/bns/BN13 Benefits Survey 2014.pdf

IFS. (2016). Personal taxes and benefits. Retrieved from:

http://www.ifs.org.uk/uploads/budgets/budget2016/budget2016 sa.pdf

Jordan, B. (2006). Social Policy for the Twenty-First Century: New Perspectives, Big Issues. Oxford:

Polity Press.

Keep, M. (2016). House of Commons Library Briefing Paper. Budget 2016: A summary. Retrieved from: http://researchbriefings.files.parliament.uk/documents/CBP-7536/CBP-7536.pdf

Kennedy, S. (2015). House of Commons Library Briefing Paper Introduction of Personal Independence Payment. Retrieved from:

http://researchbriefings.files.parliament.uk/documents/SN06861/SN06861.pdf

OECD. (2014). Social Expenditure Update. Social spending is falling in some countries, but in many others it remains at historically high levels. Insights from the OECD Social Expenditure database. Retrieved from http://www.oecd.org/els/soc/OECD2014-Social-Expenditure-Update-Nov20148pages.pdf

Oliver, M. (2013). The social model of disability: thirty years on. Disability and Society. 28:7, 10241026, DOI: 10.1080/09687599.2013.818773

Parliamentary written question (18 ${ }^{\text {th }}$ May 2016) 37130 (2016). Retrieved from:

http://www.parliament.uk/business/publications/written-questions-answers-statements/writtenquestion/Commons/2016-05-18/37130/

Politowski, B. (2016). House of Commons Library Briefing Paper. The UN Inquiry into the Rights Of Persons with Disabilities in the UK. Retrieved from:

http://researchbriefings.parliament.uk/ResearchBriefing/Summary/CBP-7367\#fullreport

Roulstone, A. (2015). Personal Independence Payments, welfare reform and the shrinking disability category. Disability and Society. 30:5, 673-688, DOI: 10.1080/09687599.2015.1021759 
Rowlingson, K. (2011). Does income inequality cause health and social problems? York: J.Rowntree Foundation

Shaw, J. (2014). PIP: process, problems and pragmatism (Child Poverty Action Group). Retrieved from: http://www.cpag.org.uk/content/pip-process-problems-and-pragmatism

SMCPC. (2015). Social mobility and child poverty commission. State of the Nation 2015: Social Mobility and Child Poverty in Great Britain. London: SMCPC

UK Government. (2016). The United Kingdom Government Response to the Report by the United Nations Committee on the Rights of Persons with Disabilities under article 6 of the Optional Protocol to the Convention. Retrieved from: http://www.ohchr.org/Documents/HRBodies/CRPD/CRPD.C.17.R.3-ENG.doc

United Nations. (2016). Committee on the Rights of Persons with Disabilities: Inquiry concerning the United Kingdom of Great Britain and Northern Ireland carried out by the Committee under article 6 of the Optional Protocol to the Convention . Retrieved from:

http://www.ohchr.org/Documents/HRBodies/CRPD/CRPD.C.15.R.2.Rev.1-ENG.doc

Wilkinson, R. and Pickett, K. (2010) The Spirit Level: Why Equality Is Better For Everyone. London: Penguin

YouGov. (2016). YouGov/Times Survey Results. Retrieved from: https://d25d2506sfb94s.cloudfront.net/cumulus uploads/document/iwe2t5mo0i/TimesResults 160 317 Budget\&VI W.pdf 